\title{
A STUDY ON SOCIODEMOGRAPHIC PATTERN AND SIDE EFFECTS OF ANTI-TUBERCULAR DRUGS AMONG TUBERCULOSIS PATIENTS IN POKHARA VALLEY
}

\author{
Bhattarai $\mathbf{S}^{1}$, Thapa $\mathrm{P}^{2}$, Shrestha $\mathrm{C}^{3}$, Dangol $\mathrm{S}^{4}$, Niroula $\mathrm{T}^{5}$, Verma $\mathrm{SC}^{6}$ \\ ${ }^{1}$ Kathmandu Univesity, Dhulikhel, Kavre \\ ${ }^{2}$ Pokhara University, Pokhara, Nepal \\ ${ }^{3}$ Deurali Janta Pharmaceutical Pvt. Ltd., Kathmandu, Nepal \\ ${ }^{4}$ Ohm Pharmaceuticals Laboratories Pvt. Ltd., Bhaktapur, Nepal \\ ${ }^{5}$ Patty Drive Maryville IL, 62062 USA \\ ${ }^{6}$ National Tuberculosis Centre, Thimi, Bhaktapur, Nepal
}

\begin{abstract}
Introduction: Tuberculosis is an infectious disease that mainly affects the lungs. Tuberculosis is one of the leading causes of morbidity and mortality in most developing countries. The SAARC region accounts more than $32 \%$ of global burden with 0.6 million deaths every year and 2.5 million new cases annually. The main aim of our study was to determine the socio-demographic patterns among tuberculosis patients in Pokhara Valley and side effects of anti tubercular drugs.

Methodology: This study was conducted among 199 tuberculosis patients at Western Regional Tuberculosis Center, Pokhara, Nepal. These patients diagnosed as new as well as retreatment pulmonary tuberculosis cases were interviewed. Study variables such as age, gender, ethnicity, side effect encountered during the treatment, smoking and alcohol habit, socioeconomic status were statistically analyzed.

Results: Among the 199 patient enrolled, 167(84\%) patients were found to have one or more side-effects. Significant relation was found between smoking and alcohol intake, socioeconomic status and disease occurrence. Prevalence of tuberculosis was higher among Gurungs. Conclusion: Socio-demographic factors also significantly influence the occurrence of tuberculosis. The side effects of anti-tuberculosis drugs are more prevalent among the age group 19 to 65 years as compared to age group of 66 years and above.
\end{abstract}

Key words: Ethnic groups, Mycobacterium tuberculosis, Socioeconomic status, Tuberculosis

\section{INTRODUCTION}

Tuberculosis (TB) is an infectious disease that usually affects lungs but it can also affect almost any part of the body. Tuberculosis is one of the leading causes of the morbidity and mortality in most developing countries. ${ }^{1}$ It is responsible for the deaths occurring in the most productive age group of between fifteen and forty-nine years because

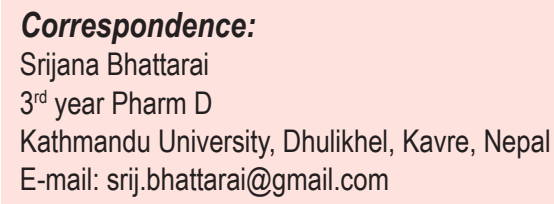

of several underlying factors. The disease can be treated and prevented if sufficient education and awareness is brought for early diagnosis and initiation of treatment. Mycobacterium tuberculosis (and occasionally Mycobacterium africanum) is the causative organisms, also known as tubercle bacilli and as acid-fast bacilli (AFB). ${ }^{2}$

The South Asian Association for Regional Cooperation (SAARC) region accounts for more than $32 \%$ of global burden of TB with 0.6 million deaths every year and 2.5 million new cases annually. ${ }^{3}$ More than 75 percent of morbidity and mortality due to the disease occur in the most economically productive age groups of $15-49$ years. ${ }^{4}$ 
In Nepal, $45 \%$ of the total population is infected with TB, out of which $60 \%$ are in the productive age group. ${ }^{5}$ One of the studies done using different tools like focus groups and interviews, have identified religion, socioeconomic status, level of education, and gender as possible factors associated with TB. ${ }^{6}$

In the context of Nepal very limited study has been done regarding the factors affecting the occurrence and treatment of tuberculosis so this study will serve as a reference for determining such underlying factors. Further, the findings of this study will be utilized by the National Tuberculosis Programme to address these factors as an interventional strategy during its future planning.

\section{METHODOLOGY}

This study was conducted at Western Regional Tuberculosis Center which was established for the prevention, treatment and control of tuberculosis in the Western Region of Nepal. Patient visiting the center between the month of May and July 2006 were selected for the study. In the study, out of 219 patients, only 199 patients were selected for the study according to the inclusion criteria.

\section{Inclusion Criteria:}

- Outpatients, pulmonary tuberculosis patients visiting the centre and willing to participate in this study.

- New or retreatment pulmonary tuberculosis patients aged 5 years and above of either sex (es).

- New or retreatment pulmonary tuberculosis patients in the continuation phase or those who have been taking medication for at least 2 or 3 months.

\section{Exclusion Criteria:}

- New or retreatment pulmonary tuberculosis patients who had just started therapy.

- Pulmonary tuberculosis patients $<5$ years of either sex (es).

- Patients with any other pre-existing immunodeficiency disease.
The tool used was a set of prepared questionnaire for each patient whose diagnosis was based on clinical evidences made by the doctor and/or other diagnostic test reports. All the patients were directly interviewed for the information as specified in the questionnaire. The study variables were age, gender, ethnicity, side effects of drugs, smoking habit, alcohol consumption and socioeconomic status of the patient.

The study was approved by the Department of Pharmacy, The School of Pharmaceutical and Biomedical Sciences, Pokhara University. Written consent was taken from the patients before enrolling them in the study. The collected data were analyzed using SPSS 15. Descriptive statistics and Pearson's correlation coefficient were used for analysis.

\section{RESULTS}

Among the 199 patients enrolled in the study, 167 patients were found to have one or more side effects. Among 167 patients; percentage of side effects was $36 \%$ in 19-65 age group (adult), $34 \%$ in 66 and above (elderly), and 30\% in 5-18 (child). Side effects such as joint pain, ototoxicity, visual disturbance, giddiness and vertigo were predominant in the adult group. The number of female patient with the active pulmonary TB was found to be 67 and that of the male as 132 . Other sociodemographic data is given in table 1 . A positive correlation of 0.139 was found between degree of smoking and occurrence of TB. Similarly a positive correlation of 0.157 was found between alcohol intake and disease occurrence. The degree of association between socioeconomic status and disease occurrence was -0.34 , which signifies negative correlation. Different ethnic groups like Chhetri, Newar, Gurung, Magar, Tamang and others (Thakali, BK, Rai, Lama, Sherpa, Pariyar, Nepali, Chaudhary) were in the study. Greater percentages of patients were found to be Gurung $(27 \%)$, probably because this group is dominant in the Pokhara valley area of the western region of Nepal. 


\begin{tabular}{|l|l|l|}
\hline \multicolumn{3}{|c|}{ Table 1. Socio-demography of tuberculosis patients } \\
\hline Sociodemography & Categorization & Percentage \\
\hline \multirow{2}{*}{$\begin{array}{l}\text { Age related side } \\
\text { effect }\end{array}$} & $1-18$ yrs & $30 \%$ \\
& $19-65$ years & $36 \%$ \\
& 66 yrs onwards & $34 \%$ \\
\hline \multirow{2}{*}{ Gender } & Male & $66.3 \%$ \\
& Female & $33.7 \%$ \\
\hline \multirow{3}{*}{ Smokers } & Yes & $74.8 \%$ \\
& No & $25.2 \%$ \\
\hline \multirow{4}{*}{ Alcoholics } & Yes & $61.4 \%$ \\
& No & $38.6 \%$ \\
\hline \multirow{5}{*}{ Ethnic groups } & Gurung & $27 \%$ \\
& Others & $26 \%$ \\
& Brahmin & $15 \%$ \\
& Chhetri & $15 \%$ \\
& Magar & $7 \%$ \\
& Newar & $6 \%$ \\
& Tamang & $4 \%$ \\
\hline
\end{tabular}

\section{DISCUSSION}

In our study we found that the prevalence of side effects was high in the adult age group Different studies have shown that the occurrence of side effect is higher in elderly. But according to our study there is very little difference in the occurrence of side effects between elderly and adult age group. However literatures suggests that elderly people were nearly three times more likely to have adverse reactions to anti-tuberculosis drugs, six times more likely to die from tuberculosis and over twenty times more likely than younger patients to have the diagnosis made at autopsy rather than during life. ${ }^{7}$ Another study has shown older age as a risk factor for intolerance of anti-TB therapy where the frequency of side-effects leading to modification of treatment was $2.3 \%$ in the $0-19$ yrs age group in contrast to $8.4 \%$ for those aged $\geq 60 \mathrm{yrs}^{8}{ }^{8}$ The incidence of pulmonary TB in our study was higher for male than female. Similar was the finding in one study where incidence of pulmonary TB $(58 \%)$, was higher in men than in women. ${ }^{9}$ There is a clear association between smoking and reduced local immunity within the lungs. In smokers, the mucous membranes of the lungs are damaged and inflamed, and the hair cells paralyzed. This effect of smoking leaves the lungs vulnerable to infection, including TB. In addition to the fact that the TB bacteria are not efficiently removed after inhalation, chronic lung damage impairs the lung immunity and may increase susceptibility to TB. Another study reported a relative risk for heavy smokers (400 cigarettes/year) of $2.17(95 \% \mathrm{Cl}$ 1.29 to 3.63$)$ compared with non-smokers. ${ }^{10}$ The literatures also suggest that alcohol consumption can increase health problems and occurrence of infectious diseases. There is clinical evidence of increased incidence of infections among alcoholics. ${ }^{11}$ Chronic alcoholism is associated with tuberculosis and chronic alcoholics have increased incidence of bacterial pneumonia by suppressing the immune system. ${ }^{11}$ Another study shows that nearly four out of fifty patients (which accounts for $8 \%$ ), developed hepatotoxicity. The incidence obtained is much higher than previous studies from USA and UK. ${ }^{12}$ The incidence of hepatotoxicity has been reported to be higher in developing countries, and factors such as acute or chronic liver disease, poor nutrition, widespread parasitism, chronic infections, indiscriminate use of various drugs, ethnic factors, severity of the disease, chronic alcoholism or genetic predisposing may play a role individually or collectively. ${ }^{12}$ In developing country like Nepal where $42 \%$ of the total population are below the poverty line $45 \%$ of the population is infected with TB out of which $60 \%$ are in economically productive age group of $15-49$ years. ${ }^{13}$ Although implementation of cost effective and highly successful treatment strategy of DOTS was started in April 1996 and has already proven its efficacy in Nepal, but still 5000-7000 people continue to die of TB every year. ${ }^{13}$ Low socioeconomic status, particularly lack of money are important risk factors for the occurrence and nonadherence to TB treatment in a poor country like Nepal. ${ }^{14}$

\section{CONCLUSION}

This study found that the productive age group is more prone to the side effects of antitubercular drugs. Similarly there are several socio-demographic factors such as age, gender, ethnicity, smoking habit, alcohol intake and socioeconomic status of the patient which also significantly influence the occurrence of disease. This study will also help National Tuberculosis Control Programme of Nepal to address these 
factors as an interventional measure during their short term as well as long term strategic planning for tuberculosis control.

\section{ACKNOWLEDGEMENT}

The authors would like to acknowledge all technical and non technical staffs of Pokhara University and Western Regional Tuberculosis Center, Pokhara. The authors also declare that they have no conflict of interest and no funding source.

\section{REFERENCES}

1. Enarson DA, Rieder HL, Arnadottir T, Trebucq A. Tuberculosis Guide for Low Income Countries. International Union against Tuberculosis and lung Disease 1996;2:1-5.

2. McAdam JM. Combating TB and Homeless. St. Vincent's Hospital and Medical Center of New York. Department of Community Medicine 1999

3. World Health Organisation. Health Development in the South East Asia Region. An overview. World Health Organization, Geneva 2004.

4. Park K. Epidemiology of Communicable Disease. In: Park's Text Book of Preventive and Social Medicine. India: Bhanol Publishers 2002;137-50.

5. Nepal Government. National TB Control Programmme Progress Report. Nepal Tuberculosis Center Thimi, Bhaktapur, Nepal 2003/2004

6. $\mathrm{M} \mathrm{K}$ Aaron, Pungrassami $\mathrm{P}$ and Nilmanat $\mathrm{K}$ et. Al, Socio-demographic and AIDS-related factors associated with tuberculosis stigma in southern Thailand: a quantitative, cross-sectional study of stigma among patients with TB and healthy community members. BMC Public Health 2011;11:675
7. William AP. Drugs Used In Chemotherapy of Tuberculosis, Mycobacterium avium Complex Disease, and Leprosy. In: Goodman and Gilman's, Hardman JG and Limbird LE. The Pharmacological Basis of Therapeutics. Texas: Mc Graw Hill Publishers 2001;1273-74.

8. Teale C, Goldman JM, Pearson SB. The Association of Age with the Presentation and Outcome of Tuberculosis: a Five-year Survey. Oxford Journals of Age and Ageing 1993;22:289-93.

9. Schaberg T, Rebhan K, Lode H. Risk factors for side-effects of isoniazid, rifampin and pyrazinamide in patients hospitalized for pulmonary tuberculosis. European Respiratory Journal 1996;9:2026-30.

10. Corona ME, Garcia LG, Riemer KD et al. Gender differentials of pulmonary tuberculosis transmission and reactivation in an endemic area. Thorax. 2006;61:348-53.

11. Olappan C, Gopi PG. Tobacco smoking and pulmonary tuberculosis. Thorax 2000;57:964-66.

12. Engs RC, Benson MA. The Association of Alcohol Consumption with Self-Reported IIIness. Psychological Reports 1995;76:727-36.

13. Shakya R, Rao BS, Shrestha B. Evaluation of Risk Factors For Antituberculosis Drugs-Induced Hepatotoxicity In Nepalese Population. Kathmandu University Journal of Science, Engineering And Technology 2006;2:1-8.

14. Shrestha K. HIV/AIDS and TB Co-infection. In: Second Annual International Students' Parers Competition on TB. Kathmandu, Nepal 2003;1-15. 